\title{
Renal denervation for the management of resistant hypertension
}

\author{
This article was published in the following Dove Press journal: \\ Integrated Blood Pressure Control \\ 3 December 2015 \\ Number of times this article has been viewed
}

\begin{abstract}
Renal sympathetic denervation (RSD) as a therapy for patients with resistant hypertension has attracted great interest. The majority of studies in this field have demonstrated impressive reductions in blood pressure (BP). However, these trials were not randomized or shamcontrolled and hence, the findings may have been overinflated due to trial biases. SYMPLICITY HTN-3 was the first randomized controlled trial to use a blinded sham-control and ambulatory BP monitoring. A surprise to many was that this study was neutral. Possible reasons for this neutrality include the fact that RSD may not be effective at lowering BP in man, RSD was not performed adequately due to limited operator experience, patients' adherence with their antihypertensive drugs may have changed during the trial period, and perhaps the intervention only works in certain subgroups that are yet to be identified. Future studies seeking to demonstrate efficacy of RSD should be designed as randomized blinded sham-controlled trials. The efficacy of RSD is in doubt, but many feel that its safety has been established through the thousands of patients in whom the procedure has been performed. Over $90 \%$ of these data, however, are for the Symplicity ${ }^{\mathrm{TM}}$ system and rarely extend beyond 12 months of follow-up. Long-term safety cannot be assumed with RSD and nor should it be assumed that if one catheter system is safe then all are. We hope that in the near future, with the benefit of well-designed clinical trials, the role of renal denervation in the management of hypertension will be established.
\end{abstract}

Keywords: resistant hypertension, renal denervation, sympathetic nervous system, symplicity

\section{Introduction}

Hypertension is a major cause of cardiovascular morbidity and mortality. ${ }^{1}$ Pharmacological therapies have significantly improved the outcomes of those with the condition. However, an estimated $50 \%$ of the hypertensive population remain uncontrolled with a blood pressure (BP) $>140 / 90 \mathrm{mmHg}$, of whom a subgroup fulfill the diagnostic criteria for resistant hypertension. ${ }^{2}$

For those with resistant hypertension, pharmacological therapy is inadequate and alternative options are required. An overactive sympathetic nervous system (SNS) has long been shown to be an important driver of hypertension. ${ }^{3,4}$ Indeed, before the advent of orally effective and safe BP lowering drugs in the 1950s, surgical sympathetic denervation was offered to those patients with malignant hypertension. ${ }^{5}$ Recent technological advances have enabled physicians to reinvent this historic treatment by performing denervation of the renal sympathetic nerves through a percutaneous route. Initial clinical trials suggested that renal sympathetic denervation (RSD) could revolutionize the landscape of therapy for resistant hypertension, but more recent developments have cast a shadow of doubt over this concept. ${ }^{6-9}$
Correspondence: Hitesh C Patel NIHR Cardiovascular Biomedical Research Unit, Royal Brompton Hospital, London SW3 6NP, UK

Tel +44207352 8I2I ext 2920

Fax +44 2073518184

Email dochiteshpatel@hotmail.com; h.patel3@rbht.nhs.uk 
In this review, we will discuss the physiological basis for sympathetic denervation as a treatment for hypertension. We will review the technology that underpins RSD devices and discuss the preclinical and clinical evidence.

\section{The sympathetic nervous system in hypertension}

There is a large body of evidence to support the hypothesis that elevated SNS activity is intimately involved in the initiation and maintenance of hypertension, and a positive correlation between SNS activity and BP has been documented. ${ }^{3,4,10}$ Hypertensive patients in whom adverse prognostic markers are present, such as those with renal failure, heart failure, or left ventricular hypertrophy, are recognized to have greater SNS activation than those without these adverse markers. ${ }^{3}$ Furthermore, medications that attenuate the SNS, including inhibitors of the renin-angiotensin-aldosterone system and moxonidine are known to lower $\mathrm{BP}^{3,11}$

The SNS is pervasive and provides innervation to every organ in the human body. ${ }^{12}$ In patients with hypertension, the increased activity of the SNS is not universal as some organs are spared. Increased noradrenaline (the key neurotransmitter of the SNS) spillover has been observed in cerebral, cardiac, and renal circulations but not in pulmonary or splanchnic when unmedicated hypertensive individuals were compared to normotensive controls. ${ }^{13}$ Furthermore, increased SNS discharges to muscle but not skin have been demonstrated with microneurography in patients with hypertension. ${ }^{14}$ This suggests that therapies to attenuate SNS overactivity should target key organs, which include the kidneys. ${ }^{15}$

\section{Renal sympathetic innervation}

The kidneys are innervated by both efferent (from the central nervous system) and afferent (to the central nervous system) sympathetic nerves. ${ }^{16}$ The majority of nerves are unmyelinated type $\mathrm{C}$ fibers. ${ }^{17}$ The efferent nerves are approximately 25 times more abundant than afferent nerves. ${ }^{18}$ Stimulation of the efferent nerves in several animal models has been shown to increase renin secretion through the direct action of noradrenaline on $\beta$-adrenoreceptors on juxtaglomerular cells, promote sodium and water reabsorption at the tubular level via activation of $\alpha$-adrenoreceptors, and reduce renal blood flow and glomerular filtration through vasoconstriction, all of which are important mechanisms in the pathophysiology of hypertension. ${ }^{16,17,19}$ In a subgroup of ten patients from the SYMPLICITY HTN-1 trial, RSD was able to attenuate renal efferent nerve activity with a mean $47 \%$ reduction in noradrenaline spillover. ${ }^{20}$
The role of the afferent renal nerves in the genesis of hypertension is less well established. There are two main types of afferent nerves, both predominately found in the renal pelvis; one is chemosensitive and responds to nociception (adenosine, ischemia, acidosis, inflammation, oxidative stress, and angiotensin II) and the other is mechanosensitive (also found in the renal cortex) and responds to stretch. ${ }^{16,21}$ In animal models, stimulation of the afferent system activates central nervous system centers known to be involved in cardiovascular regulation. ${ }^{17}$ Conversely, interrupting the afferent nerves in diseased states reduces central sympathetic outflow particularly to the heart, the kidneys, and peripheral vasculature. ${ }^{4,17,22}$ In humans, peroneal nerve microneurography has been used to demonstrate reduced central nervous system sympathetic discharge after afferent (and efferent) renal denervation following nephrectomy in patients with end-stage renal failure ${ }^{23}$ and after RSD in a patient with hypertension. ${ }^{22,24}$

\section{Surgical sympathetic denervation}

Surgical denervation of the renal nerves in both small and large animal models of hypertension, have either prevented the onset of hypertension or attenuated its magnitude. ${ }^{15}$

In man, limited historic data suggest that nonselective sectioning of the sympathetic nerves to the thorax and abdomen improved BP control and even survival in patients with malignant hypertension. ${ }^{5,25,26}$ However, success rates were variable and side effects such as hypotension, incontinence, and sexual dysfunction were common, leading to the demise of nonselective surgical sympathectomy once pharmacological therapies were introduced. ${ }^{25,26}$

The renal transplant medicine literature provides more contemporary data on the effects of selective surgical renal sympathectomy. First, newly transplanted kidneys can function despite the absence of functioning efferent or afferent renal nerves. Second, over time damaged efferent nerves begin to reinnervate the kidney and this process is usually complete by 12 months. ${ }^{27,28}$ More data are available from animal models, which suggest that the reinnervation is not just anatomical but also functional and involves both efferent and afferent nerves. ${ }^{29-31}$ Third, nonfunctioning kidneys can promote hypertension through neurohumoral activity. In a selected population of patients with hypertension persisting after renal transplant, native kidney nephrectomy (which involves sectioning of the renal nerves) was associated with improved BP control as well as allograft perfusion. ${ }^{32}$ Selective renal sympathectomy (with nephrectomy) was not associ- 
ated with the significant side effects seen in the nonselective sympathectomy cohort.

\section{Resistant hypertension}

The reported prevalence of uncontrolled hypertension varies according to the definition used but is estimated at $30 \%-50 \%$ of the population diagnosed with hypertension. ${ }^{2,33}$ Within this group there is a smaller group, who have true resistant hypertension, which can be diagnosed when patients have an office BP $>140 / 90 \mathrm{mmHg}$ and a mean 24-hour ambulatory $\mathrm{BP}>130 / 80 \mathrm{mmHg}$ despite being compliant with three or more different classes of antihypertensive medications including a diuretic. ${ }^{34}$ There is evidence that this group forms $5 \%-10 \%$ of the hypertension population, and patients of this group suffer a greater incidence of cardiovascular complications than the group of patients with controlled BP. ${ }^{35}$ The management of this cohort of patients is challenging, and one approach is summarized in Figure 1.

Frustratingly, there have been no new classes of antihypertensives added to the specialist's armory in recent times (since 2000, the only newly approved class has been direct renin inhibitors). ${ }^{36}$ Building on previous decades of knowledge of the increased activity of the sympathetic nerves in hypertension, coupled with the increased experience in minimally invasive procedures in cardiology, it was a logical step to develop and reexamine nonpharmacological techniques to attenuate the SNS. Currently, there are four main autonomic nervous system modulating devices under investigation for the management of resistant hypertension: RSD catheters, baroreceptor stimulators, vagal nerve stimulators, and spinal cord stimulators (Figure 2). ${ }^{12}$ In this review we will focus on RSD.

\section{Principles of percutaneous RSD Renal anatomy}

The goal of RSD is to permanently destroy a large proportion of the renal sympathetic nerves. There have been only two contemporary publications, both based on cadaveric human data that usefully describe renal nerve anatomy in man. The first studied nine renal arteries suggested that over $90 \%$ of the renal nerves are within $2 \mathrm{~mm}$ of the renal artery lumen (lumen-intima interface). However, these data were biased as the investigators only examined nerves up to $2.5 \mathrm{~mm}$ from the lumen and used inadequate histological sectioning. ${ }^{37}$

The second paper studied more renal arteries (20 in total), included vessels that had been exposed to hypertension in vivo and employed more comprehensive histological techniques (perfusion-fixing at physiological pressures, assessment of complete periarterial nerve distribution, not just those encountered in the first $2.5 \mathrm{~mm}$ and application of immunohistochemistry to distinguish afferent from efferent nerves).$^{38}$ Their key findings were as follows:

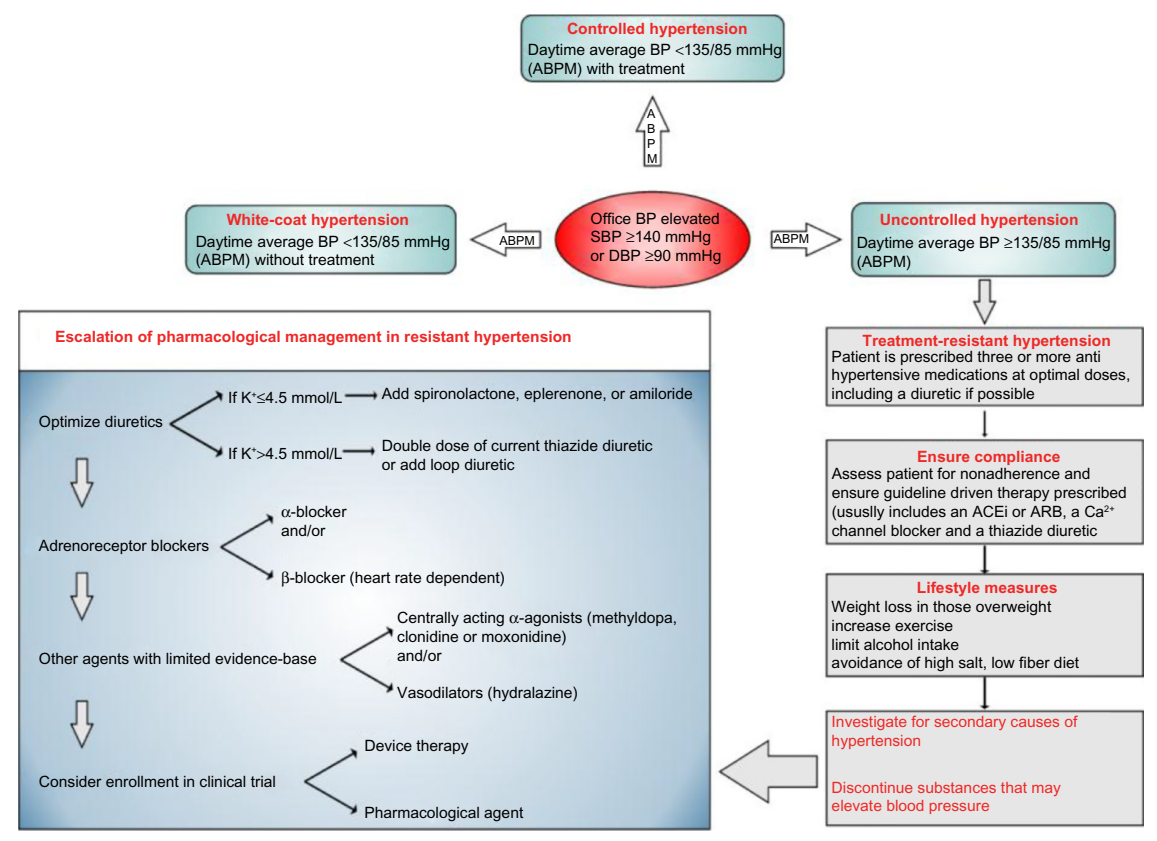

Figure I Flowchart summarizing the diagnosis and management algorithm in patients with resistant hypertension.

Note: Reproduced from Patel H, Hayward C, de Silva R. An approach to diagnosis and management of resistant hypertension. J Pract Cardiovasc Sci. 20I5; I ( ):60-64 (http:// creativecommons.org/licenses/by-nc-sa/3.0/)..$^{34}$

Abbreviations: ABPM, ambulatory blood pressure monitor; BP, blood pressure; SBP, systolic blood pressure; DBP, diastolic blood pressure; ACEi, angiotensin converting enzyme inhibitor; $\mathrm{ARB}$, angiotensin II receptor blocker; $\mathrm{Ca}^{2+}$, calcium; $\mathrm{K}^{+}$, potassium. 


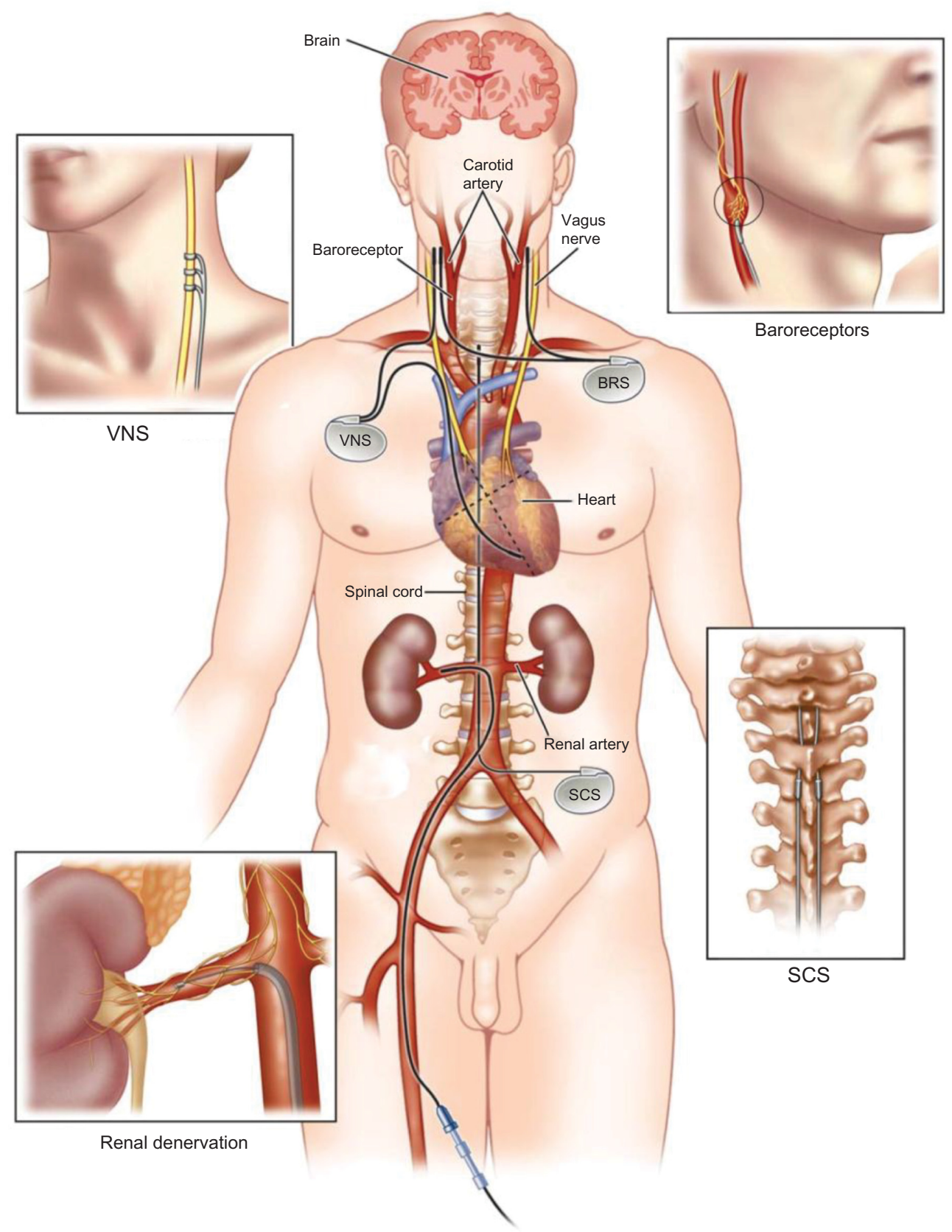

Figure 2 The four sites of action of autonomic nervous system modulating devices.

Note: Reprinted from International Journal of Cardiology, 170(2), Patel HC, Rosen SD, Lindsay A, Hayward C, Lyon AR, di Mario C, Targeting the autonomic nervous system: measuring autonomic function and novel devices for heart failure management, 107-117, Copyright (C) (2013), with permission from Elsevier. ${ }^{2}$

Abbreviations: BRS, baroreceptor stimulator; VNS, vagal nerve stimulator; SCS, spinal cord stimulator.

1. Renal nerve anatomy in hypertensive patients is similar to the anatomy in those with normal BP.

2. The number of nerves are greater around the proximal and middle segments of the renal artery than the distal.

3. The nerves approximate closer to the renal artery lumen as they progress from the aorta to the renal hilum. Prior to any renal artery bifurcation, $90 \%$ of the renal nerves are within $6.4 \mathrm{~mm}$ of the renal artery lumen. However, after any bifurcation, $90 \%$ of the nerves are within $3 \mathrm{~mm}$ of the lumen.
4. A larger proportion of nerves pass anterior, superior, and inferior to the renal artery as opposed to posterior to it.

5. Sympathetic nerves are also associated with smaller accessory renal arteries.

Based on these data, the renal sympathetic nerves lie in close proximity to the renal artery (usually within the adventitia), and it is conceivable that they could be targeted by thermal energy using either radio frequency (RF) or ultrasound (US) delivered from a catheter within the renal artery lumen. ${ }^{39}$ 
The original RSD trials in humans recommended that all ablations should be limited to the main vessel before any bifurcations. ${ }^{6,7}$ However, the latest histology data suggest that it might be preferential to target the distal vessel, where the renal nerves lie closer to the arterial lumen. Henegar et $\mathrm{al}^{40}$ compared the effects of RSD at the renal artery ostium, main renal artery before any bifurcation and postbifurcation upon renal noradrenaline levels in pigs. They concluded that a strategy of performing postbifurcation ablation was more effective at attenuating the activity of the renal SNS. This approach is yet to be translated to humans and, at present, should only be undertaken within the auspices of a clinical trial to ensure there are no safety concerns from possible thermal injury to the psoas muscles, small bowel, and liver. ${ }^{41}$

\section{Biophysics and denervation catheters}

During RSD, electrical energy at the denervation catheter tip is converted to either RF or US energy, which penetrates through the renal artery wall and "excites" the periartery cells. ${ }^{39}$ This "excitation" creates friction between the cells generating thermal energy. Once the tissue temperature reaches $50^{\circ} \mathrm{C}$, irreversible cell death ensues and a lesion is created. Though the penetration of RF and US energy is likely to be just a few millimeters, the lesion depth extends further than this due to conduction of thermal energy from the initial and more superficial structures that are heated first. ${ }^{39}$

Factors that influence the size of lesion created include power delivery, electrode-tissue contact, tissue impedance, and tissue temperature. ${ }^{39}$ During a procedure, the operator only has the ability to alter electrode-tissue contact. Power delivery is governed by proprietary and automated algorithms driven by measurement of tissue impedance and temperature taken at the electrode tip. There are six RSD systems with the Conformité Européenne mark, each with important design variations, such that their efficacy and safety should be considered individually rather than as a class-effect (Table 1).

The Spyral ${ }^{\mathrm{TM}}$ (Medtronic, Dublin, Ireland) and Vessix ${ }^{\mathrm{TM}}$ (Boston Scientific, Marlborough, MA, USA) system may be used in renal arteries with diameters as small as $3 \mathrm{~mm}$, whereas with all the others a minimum artery diameter of $4 \mathrm{~mm}$ is recommended. The Iberis ${ }^{\mathrm{TM}}$ (Terumo Medical Corporation, Tokyo, Japan) and the Radiance ${ }^{\mathrm{TM}}$ (5Fr version of

Table I Currently available CE-marked renal denervation catheters

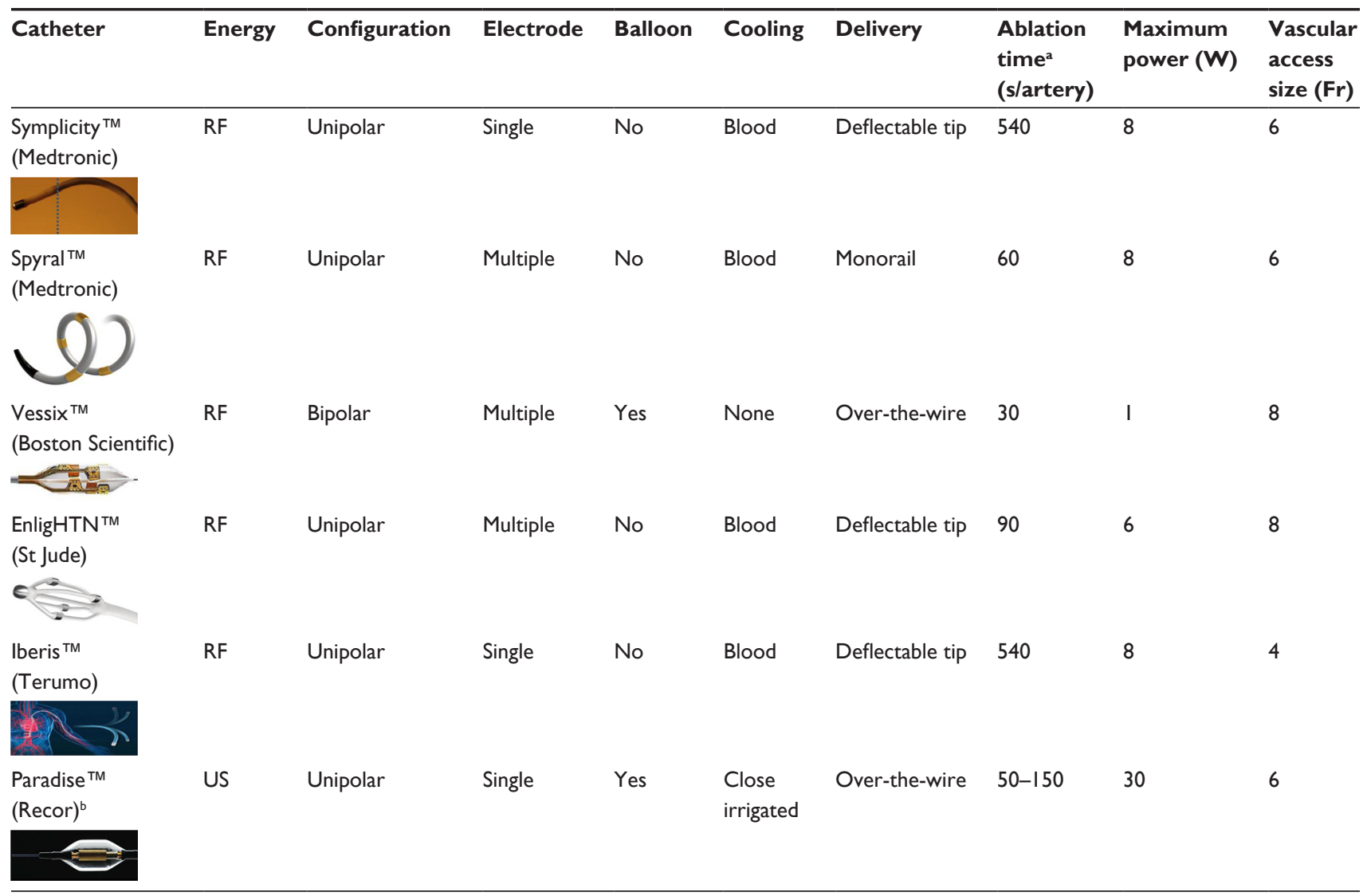

Notes: aMinimum estimated time of RF delivery; ${ }^{b}$ there is also a $5 \mathrm{Fr}$ version of Paradise ${ }^{\mathrm{TM}}$ called Radiance ${ }^{\mathrm{TM}}$ that may be used via the radial artery. Abbreviations: RF, radiofrequency; US, ultrasound; CE, Conformité Européenne. 
Paradise $^{\text {TM }}$ [Recor, Amsterdam, the Netherlands]) catheters can be used via the radial artery approach (all other catheters mandate operation through the femoral artery).

The maximum lesion size created by these catheters remains poorly reported..$^{41}$ A recent review identified only four publications that adequately detailed lesion characteristics involving only the Symplicity ${ }^{\mathrm{TM}}$ (Medtronic), EnligHTN ${ }^{\mathrm{TM}}$ (St Jude, St Paul, MN, USA), and Paradise ${ }^{\mathrm{TM}}$ systems. ${ }^{41}$ The maximum depth of thermal injury varied from 2 to 12 mm. ${ }^{18,42,43}$ There needs to be more clarity about the capabilities of each system as catheters that are able to create deeper lesion might disrupt a greater proportion of periarterial nerves and hence, be more efficacious, though this would have to be balanced against the increased risk of inadvertent damage to other abdominal structures. ${ }^{41}$ Recently, standards on reporting of preclinical evaluation of RSD have been published and should hopefully help improve our understanding of efficacy and risks of the various denervation systems. ${ }^{44}$

It should also be noted that currently, it is not recommended to perform RSD in regions of the renal artery with significant renal atheroma. Two underlying reasons for this are as follows: 1) the safety of this approach is unknown, in particular whether it may cause plaque rupture or accelerate atheroma progression; and 2) it is doubtful whether the radiofrequency energy will be able to penetrate through the atheroma to the adventitia, where the sympathetic nerves are and therefore, might expose the patient to risk without any likely benefit.

\section{The renal denervation procedure}

The procedure is performed in an angiography suite. Local anesthesia is used for arterial access. Intravenous opioids and sedation are required during the application of RF or US energy as this always stimulates the C-type pain fibers associated with the renal sympathetic nerves. Intravenous heparin is administered during the procedure. Some centers also advocate 2-4 weeks of antiplatelet agents to minimize the risk of intra-arterial thrombus formation. Fluoroscopy with radio-opaque contrast is employed to position the chosen RSD catheter in the renal artery.

The original ablation strategy was that four to six lesions would be created in a helical pattern (such that all four segments of the artery were treated) in both renal arteries in the proximal or middle segments prior to any major bifurcation (Figure 3). To those who have performed RSD, it is apparent that when using the single electrode design catheters (Symplicity $^{\mathrm{TM}}$ or Iberis ${ }^{\mathrm{TM}}$ ), the operator cannot be certain whether the anterior or posterior segment of the renal artery
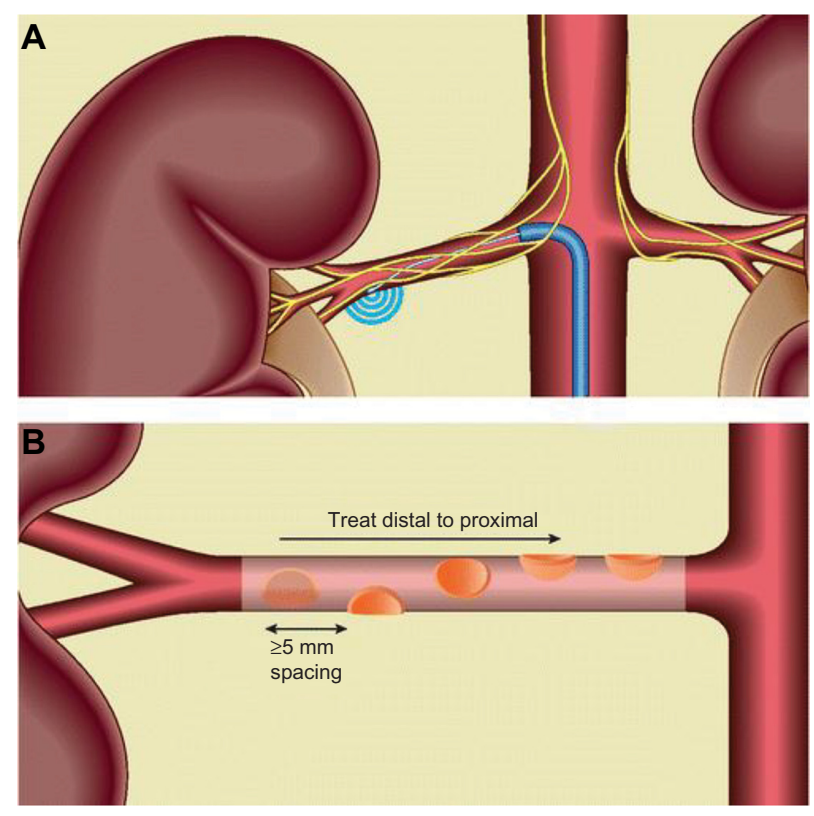

Figure 3 Renal denervation procedure using the Symplicity ${ }^{\mathrm{TM}}$ catheter (A).

Notes: Ablations are applied as shown in a helical pattern, including at least one of each anterior, posterior, superior, and inferior positions (B). Reproduced from Patel HC, Hayward C, Di Mario C. SYMPLICITY HTN 3: the death knell for renal denervation in hypertension? Glob Cardiol Sci Pract. 2014;20I4(1):94-98. ${ }^{8}$

is being treated, due to the limitation of two-dimensional fluoroscopic imaging. The multielectrode catheters (Table 1) are designed to create circumferential or helical ablation lesions in a more rapid and consistent fashion.

The biggest intraprocedural challenge that remains unresolved is the lack of a marker to inform the operator whether the ablation has been sufficient to adequately attenuate renal sympathetic nerve activity.

\section{Trials of RSD}

Initial evidence for the efficacy of a percutaneous approach in achieving sympathetic denervation came from animal studies. ${ }^{15}$ In normotensive dogs, electrical stimulation of renal nerves from within the renal artery increased systolic BP by at least $20 \mathrm{mmHg} .{ }^{45}$ However, when the stimulation protocol was repeated after percutaneous RSD, the systolic BP response was attenuated with a mean increase of only $2 \mathrm{mmHg}$. Henegar et $\mathrm{al}^{42}$ achieved a $9 \mathrm{mmHg}$ drop in mean arterial pressure in nine hypertensive and obese dogs following RSD.

The first procedure in man was performed in 2007 as part of the proof-of-concept SYMPLICITY HTN-1 study using the Symplicity ${ }^{\mathrm{TM}}$ catheter. ${ }^{6}$ It was performed across five centers in Australia and Europe. Fifty patients with office systolic BPs $>160 \mathrm{mmHg}$ despite being on three or more antihypertensives (including a diuretic) were recruited. Forty-five of these patients underwent the procedure as five 
did not have suitable renal anatomy. As an added safety feature, the first ten patients underwent staged RSD, where the second renal artery was treated 1 month after the first. This pilot study provided evidence for the safety and tolerability of RSD. After publishing the initial results, the investigators extended the pilot to 153 patients of whom 88 were followed up for 3 years. ${ }^{46}$ Four major immediate complications were reported: one renal artery dissection and three femoral artery complications (pseudoaneurysm or significant hematoma). There were four cases of renal artery stenosis in this extended follow-up cohort, and it is unclear whether these represented intrinsic disease progression or a complication of the procedure. The finding that caught the attention of the cardiology community, however, was the impressive reduction in office BP observed at 6 months of 22/10 $\mathrm{mmHg}$, which persisted with a slight further decrease after 3 years of follow-up.

The same key investigators then devised a randomized open-label trial, SYMPLICITY HTN-2. ${ }^{7}$ At 6 months postrandomization, office BP data were available for 49 patients who underwent RSD and 52 who were allocated as controls. The between-group difference in reduction in BP was $33 / 11 \mathrm{mmHg}(P<0.0001)$ in favor of the active treatment. Twenty patients in the active arm also underwent ambulatory monitoring and they achieved an 11/7 mmHg mean reduction in BP. The only significant complication reported was the occurrence of one femoral artery pseudoaneurysm.

These strong signals for efficacy and safety captured the imagination of interventionists and hypertension specialists alike. Multiple studies to investigate the efficacy of RSD were subsequently launched; the majority of which showed a 10-30 $\mathrm{mmHg}$ reduction in office systolic BP following RSD. ${ }^{47}$ If even a $10 \mathrm{mmHg}$ effect was genuine, then this would be expected to deliver an impressive $41 \%$ reduction in stroke as well as a $22 \%$ reduction in coronary heart disease events. $^{48}$

Table 2 summarizes the findings of a recent PubMed search, using the terms "renal denervation" and "hypertension" to identify unique human clinical trials. The definitions used by these trials to diagnose resistant hypertension differed, which often resulted in recruitment of patients with various stages of hypertension. The majority of the early trials did not use 24-hour ambulatory monitoring to exclude white-coat hypertension. The impact of this omission is large; in a registry of 8,295 patients with apparent resistant hypertension (office BP $\geq 140$ and/or $90 \mathrm{mmHg}$, while on three antihypertensive drugs including a diuretic), $37.5 \%$ of the cohort were reclassified as having white-coat hypertension after ambulatory monitoring. ${ }^{49}$ Patients with pseudoresistant hypertension are unlikely to benefit from RSD. ${ }^{50}$

Three-quarter of the studies to-date have been uncontrolled, which raise the concern that much of the efficacy data of RSD may be overinflated due to bias. In particular, three key biases were inherent in the majority of RSD studies: ${ }^{51}$

1. Regression to the mean: this occurs when a variable such as office BP has inherent biological variability and patients are selected on the basis of recording a high value. In doing so, the study criteria selects patients who might be having a "big-day" and experiencing higher than their usual BP; consequently, the higher the threshold for selection, the larger the statistical expectation of a fall

Table 2 Summary of the published renal denervation trials, including number of trials published, number of patients denervated using different catheters, and reported complications

\begin{tabular}{|c|c|c|c|c|}
\hline Study types & Uncontrolled $^{68-109}$ & Case-control ${ }^{110-1 / 4}$ & Randomized control ${ }^{7,9,53-58}$ & Total \\
\hline Number published & $42(76 \%)$ & $6(11 \%)$ & $7(13 \%)$ & 55 \\
\hline Number denervations & $2,7 \mid 3(73 \%)$ & $276(7 \%)$ & $743(20 \%)$ & 3,732 \\
\hline Symplicity ${ }^{\mathrm{TM}}$ & 2,533 & 237 & 730 & $3,500(94 \%)$ \\
\hline EnligHTN ${ }^{T M}$ & 58 & 0 & 0 & $58(2 \%)$ \\
\hline Paradise $^{\mathrm{TM}}$ & 11 & 0 & 0 & $\mathrm{II}(<\mathrm{I} \%)$ \\
\hline Vessix ${ }^{\mathrm{TM}}$ & 8 & 0 & 0 & $8(<1 \%)$ \\
\hline Iberis ${ }^{\mathrm{TM}}$ & 6 & 0 & 0 & $6(<1 \%)$ \\
\hline OneShot ${ }^{\mathrm{TM} a}$ & 9 & 0 & 0 & $9(<1 \%)$ \\
\hline EP & 88 & 39 & 13 & 140 (4\%) \\
\hline Complications & $38(1.4 \%)$ & $5(1.8 \%)$ & $13(1.7 \%)$ & 56 \\
\hline Renal artery & 13 & 0 & 4 & $17(0.5 \%)$ \\
\hline Renal function & 8 & 0 & 4 & $12(0.3 \%)$ \\
\hline Femoral artery & 17 & 5 & 5 & 27 (0.7\%) \\
\hline
\end{tabular}

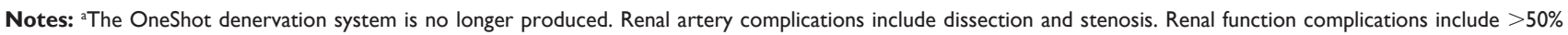
deterioration in renal function or new end-stage renal failure. Femoral artery complications include pseudoaneurysm or significant hematoma. Abbreviation: EP, cardiac electrophysiological study catheter. 
in the variable, without any intervention. The best way to mitigate the effects of this bias is to have a prolonged run-in phase with multiple BP measurements taken across several weeks prior to assess trial eligibility. ${ }^{36}$ Decreasing the BP threshold for trial entry, would also reduce the magnitude of regression to the mean: the majority of RSD trials required an office systolic BP $\geq 160 \mathrm{mmHg}$, which could be reduced to $\geq 140 \mathrm{mmHg}$ (a commoner threshold used in hypertension trials). Finally, the adoption of a randomized design would enable comparison of any responses seen in the active arm against those in the control.

2. Unintentional bias by clinical observers: typically the majority of trials have used office-measured BP as an end point. Regardless of whether the physician is blinded to the treatment allocation, they are likely to reject measurements which appear inconsistent and against expectation. It has been shown that using ambulatory BP monitoring to assess response reduces this bias. A further benefit of ambulatory monitoring is in selecting out patients who have white-coat effects and hence, do not fulfill the diagnostic criteria for resistant hypertension (Figure 1).

3. Change in adherence to therapy: it is plausible that as a result of increased attention and by exposure to an invasive procedure that trial participants became better educated on the importance of BP control and this may have improved medication adherence. Unlike in the majority of pharmaceutical trials, where preexisting antihypertensive agents are withdrawn in the run-in phase, in the denervation trials these medications are continued. When BP responses in the placebo arm of pharmaceutical double-blind randomized controlled trials (RCTs) $(n=52)$ in nonresistant hypertension were analyzed, the greater the number of nonstudy BP medications taken at randomization, the greater the reduction in BP was noted. ${ }^{36}$ The only way to account for this bias, is to either design a trial in resistant hypertension where participants are included after being withdrawn from their usual medications or perhaps more acceptable is to adopt a randomized, blinded-sham control design so that any response seen in the active arm can be balanced against that seen in the sham arm. ${ }^{52}$

The limitations of the uncontrolled, nonrandomized and unblinded trials of RSD in resistant hypertension were widely overlooked and led to a feverish uptake of this novel treatment involving thousands of patients across Europe, Asia, and Australasia.

\section{RCTs}

Six RCTs followed SYMPLICITY HTN-2 with two using a blinded sham control and ambulatory monitoring to select patients and assess their response. These trials were designed to best mitigate the previously described biases. SYMPLICITY HTN-3 was the larger of the two and randomized a total of 535 patients. ${ }^{9}$ It was primarily launched to fulfill the regulatory requirements in the USA to receive Food and Drug Administration approval. In the active arm, there was a large decrease in office $(14.1 \mathrm{mmHg})$ and ambulatory $(6.8 \mathrm{mmHg})$ systolic BP; however, this was not significantly different to the reduction seen in the BP of those in the sham-controlled arm. In subgroup analysis, RSD appeared more effective in nonblack compared to black individuals. The clinical significance of this remains unclear but suggests that there are subgroups of patients who might benefit from RSD, and more work needs to be undertaken to identify these groups better.

The neutral result of SYMPLICITY HTN-3 was unexpected and effectively curbed much of the inflated enthusiasm for performing RSD outside of clinical trials. Potential reasons for the neutrality of this trial have been widely discussed, but a frequently quoted one was that the procedure was not performed adequately. ${ }^{8}$ The trial was exclusively undertaken in the USA, where the operators had no prior experience of RSD. Only 26 of the 111 operators involved in SYMPLICITY HTN-3 had performed five or more denervations. In post hoc analysis, there was a suggestion that those patients who had more extensive and comprehensive ablations achieved a greater reduction in $\mathrm{BP}^{53}$ This suggests that the newer catheters with multiple electrodes, which were designed to deliver an anatomically comprehensive ablation, might be more effective.

The $11.7 \mathrm{mmHg}$ decrease in systolic BP seen in the sham arm of SYMPLICITY HTN-3 also received scrutiny as it was significantly different to the $1 \mathrm{mmHg}$ increase documented in the control arm of SYMPLICITY HTN-2. ${ }^{36}$ A subsequent meta-analysis estimated the expected mean systolic BP response in the blinded control arms of resistant hypertension trials to be $-8.8 \mathrm{mmHg} .{ }^{36}$ The paradoxical response seen in SYMPLICITY HTN-2 might represent a reverse Hawthorne effect, whereby patients allocated to the control arm purposefully changed their behavior (including reduced adherence to medication) to increase the likelihood of being eligible for an opportunity to crossover and receive RSD after 6 months. Blinding patients to randomization allocation would reduce this bias.

The only other trial which employed a sham control was smaller ( 35 patients allocated to RSD and 34 to control) but 
was conducted with more experienced operators in Europe. ${ }^{54}$ Though the trial failed to meet its primary end point (change in ambulatory systolic BP at 6 months as intention-to-treat), there was a suggestion of benefit on a per-protocol analysis where a significant difference between the active and sham arm of the trial was seen $(8.3$ vs $3.5 \mathrm{mmHg}, P=0.042)$. This study was, however, underpowered for its primary end point.

Two RCTs that published their findings after SYMPLICITY HTN-3 both used intensified pharmacology (IP) as an open-label active control. These studies used the Simplicity ${ }^{\mathrm{TM}}$ catheter system and employed ambulatory BP monitoring. In the Prague-15 study ( $n=106)$, the control group were administered spironolactone as an add-on therapy. However, this was associated with a higher rate of adverse events in the control arm ultimately cumulating in the discontinuation of the drug in $39 \%$ of patients. ${ }^{55}$ This study suggested that RSD is just as efficacious at lowering BP as spironolactone, but with fewer short-term side effects and greater tolerability.

The DENER-HTN $(n=101)$ trial mandated a more regimented drug escalation protocol after randomization if home BP readings were $\geq 135 / 85 \mathrm{mmHg}$. ${ }^{56}$ In contrast, the Prague-15 trial stepped-up antihypertensive treatment was allowed in both the open-control and the renal denervation arms. At the end of the study, the patients were taking more BP-lowering medications than at the start, but there remained no differences in this respect between the two arms. The study concluded that RSD with IP was more efficacious than IP alone.

SYMPLICITY HTN-Japan was an open-control trial that was discontinued early after the negative results of SYMPLICITY HTN-3. ${ }^{57}$ They had randomized 41 patients and at 6 months follow-up did not demonstrate a significant difference between the two allocation groups with respect to office systolic BP. However, it is important to note that with 41 patients only, this study was underpowered.

Finally, Pokushalov et al ${ }^{58}$ evaluated RSD in 27 patients with resistant hypertension, who were due to undergo atrial fibrillation ablation. ${ }^{58}$ Participants were randomized to have concomitant RSD using the same electrophysiology ablation catheter or nothing. This study had significant biases: 1) single-center experience, 2) small study size, 3) ambulatory BP monitoring was not used, and 4) neither the patients nor the investigators who performed the analysis were blinded to allocation. Due to these important biases, the results pertaining to BP from this study will not be discussed. ${ }^{59}$ Perhaps the most interesting finding from this study was that they showed a blunted elevation in systolic BP in response to high-frequency stimulation from within the right and left renal artery following RSD. ${ }^{58}$ This technique to assess efficacy of RSD has been reproduced by others. ${ }^{60}$

A summary forest plot of RCT data that used ambulatory BP monitoring to measure efficacy is shown in Figure 4. A formal meta-analysis of the six properly designed RCTs has further failed to show any BP lowering effect from RSD. ${ }^{61}$

\section{Safety of renal denervation}

Table 2 summarizes the reported complications in 55 studies of RSD in resistant hypertension. The overall composite complication rate is $1.5 \%$, which includes vascular access site complications (pseudoaneurysm, hematoma), renal artery injury (dissection, stenosis), and renal dysfunction ( $>50 \%$ change in renal function). The true burden of chronic complications (renal artery stenosis, deterioration in renal

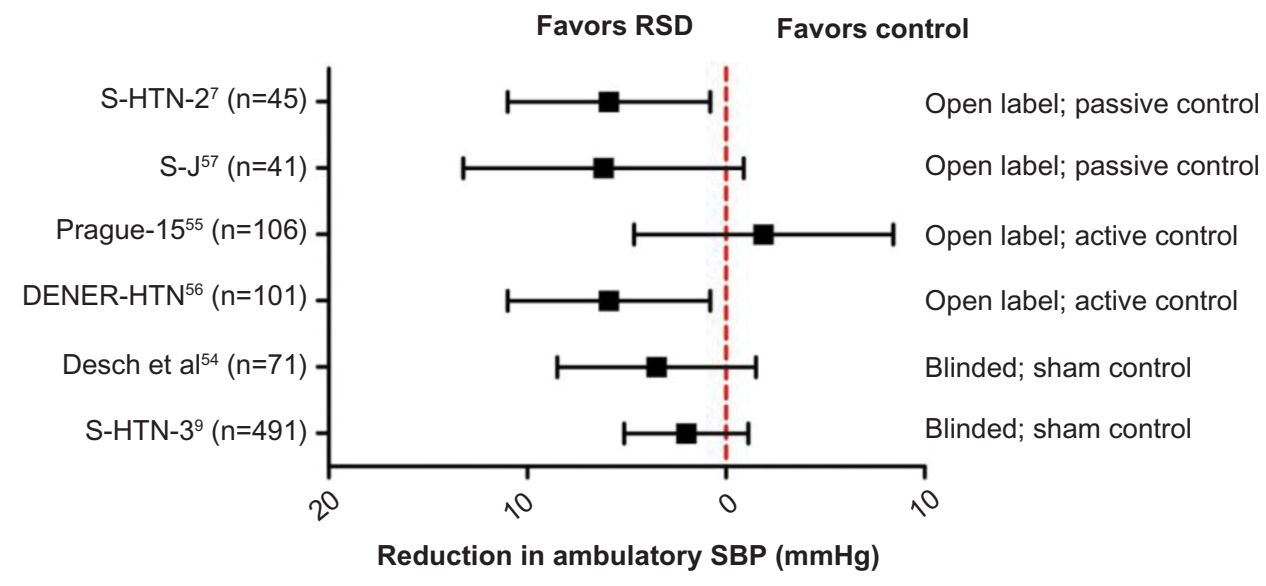

Figure 4 Forest plot showing the effect of renal denervation across key randomized controlled trial on ambulatory SBP.

Notes: Error bars denote mean effect with $95 \%$ confidence intervals.

Abbreviations: RSD, renal sympathetic denervation; SBP, systolic blood pressure; S, SYMPLICITY; J, Japanese. 
function), however, cannot be gauged as renal artery imaging has not been systematically performed after the procedure, the majority of studies are uncontrolled and therefore the natural progression in renal function in untreated patients with resistant hypertension cannot be directly obtained for comparison with those who underwent RSD, and the majority of studies did not extend beyond 6 months of follow-up and hence, there is limited data to describe any potential harmful effects beyond this time point. Finally, since more than $90 \%$ of the published RSD data have used the Symplicity ${ }^{\mathrm{TM}}$ catheter, the safety and efficacy data we have is attributable only to this system and should not be generalized to other products. Indeed, a small study using optical coherence tomography immediately after RSD found differences in the extent of vascular damage between balloon and non-balloon-based catheter systems. ${ }^{62}$ These risks and uncertainties should be communicated appropriately to patients before consenting them to what currently remains a research procedure.

\section{The future}

The future of RSD remains uncertain. Currently, the best trial evidence suggests that RSD is not effective at lowering the BP of patients with resistant hypertension. However, the future of RSD will depend on the emerging answers to the following:

1. Was the RSD technique ineffective at achieving adequate sympathetic denervation? It is difficult to deliver complete anatomical ablation with the single electrode Simplicity $^{\mathrm{TM}}$ catheter, which was adopted by the majority of trials. Future trials should use the newer multielectrode catheters and examine whether they are an improvement. Furthermore, consideration should be given to whether operators ought to target the distal renal artery, where renal nerves are in closer proximity to the arterial lumen rather than restrict themselves to prebifurcation segments. Indeed, in pigs, ablating more distally achieved a greater reduction in renal noradrenaline levels. ${ }^{40}$ Finally, the critical limitation of all RSD procedures is the lack of a reliable measure of success of denervation. The latter point encompasses both intraprocedural markers and pre- and postprocedural assessment of the SNS (there is currently no gold-standard technique to quantify the SNS).

2. Is trial design the major culprit in creating false optimism and will future trials take heed of the lessons of previous flawed trial design? Along with others, we hope that future trials will have a randomized, sham-controlled, and blinded design with particular attention to end point selection (ambulatory monitors should be used more widely to assess BP response); and adequate length of follow-up (to assess longevity of any response, ie, do the renal sympathetic nerves reinnervate ${ }^{29}$ and to establish long-term safety especially with respect to renal function and renal artery stenosis).

3. Have the wrong patients been studied? Resistant hypertension is a complicated condition to manage. Accurately diagnosing the condition for clinical study has not been performed well in the RSD trials. Very few studies used ambulatory monitors to exclude white-coat hypertension and those that did found that RSD was not as effective as previous trials. By definition, polypharmacy is a feature of resistant hypertension, and nonadherence is expected to affect up to $50 \%$ of patients. ${ }^{63,64}$ It might have been simpler to interpret a study investigating the role of denervation in mild or moderate hypertension patients, where patients could be safely weaned of any BP lowering agents prior to randomization thereby removing any effects due to change in adherence.

4. Is the hypothesis wrong? The role of the renal sympathetic nerves in hypertension has overwhelming support from preclinical and clinical studies and should not be disputed. However, the SNS is not the only pathway involved in hypertension and may not even be the most important. ${ }^{65,66}$ This is illustrated by the finding that other effective classes of antihypertensives, such as diuretics, calcium channel blockers, and $\alpha$-adrenoreceptor blockers, commonly elevate overall SNS activity.,11 Further evidence comes from an uncontrolled study of 35 patients with resistant hypertension in whom no correlation was found between the baseline or change in sympathetic nerve activity (microneurography) and change in BP following RSD. ${ }^{67}$

\section{Conclusion}

There are nine relatively small RCT and blinded trial in resistant hypertension (including drugs and devices), which is inadequate for such an important clinical problem. ${ }^{36}$ The autonomic nervous system may be an important target in this difficult-to-treat condition. We hope that soon, with the benefit of well-designed trials, we will know what role, if any, renal denervation has to play in the management of resistant hypertension.

\section{Acknowledgment}

$\mathrm{HCP}$ and $\mathrm{CH}$ are supported by the NIHR Cardiovascular Biomedical Research Unit at the Royal Brompton and Harefield NHS Trust and Imperial College London, UK. 


\section{Disclosure}

The authors report no conflicts of interest in this work.

\section{References}

1. Lewington S, Clarke R, Qizilbash N, Peto R, Collins R. Age-specific relevance of usual blood pressure to vascular mortality: a meta-analysis of individual data for one million adults in 61 prospective studies. Lancet. 2002;360(9349):1903-1913.

2. Kearney PM, Whelton M, Reynolds K, Muntner P, Whelton PK, He J. Global burden of hypertension: analysis of worldwide data. Lancet. 2005;365(9455):217-223.

3. Mancia G, Grassi G. The autonomic nervous system and hypertension. Circ Res. 2014;114(11):1804-1814.

4. Grassi G, Mark A, Esler M. The sympathetic nervous system alterations in human hypertension. Circ Res. 2015;116(6):976-990.

5. Patel H, di Mario C. Renal denervation for hypertension: where are we now? Br J Cardiol. 2013;20:142-147.

6. Symplicity HTN-1 Investigators. Catheter-based renal sympathetic denervation for resistant hypertension: durability of blood pressure reduction out to 24 months. Hypertension. 2011;57(5):911-917.

7. Symplicity HTN-2 Investigators. Renal sympathetic denervation in patients with treatment-resistant hypertension (the Symplicity HTN-2 trial): a randomised controlled trial. Lancet. 2010;376(9756):1903-1909.

8. Patel HC, Hayward C, Di Mario C. SYMPLICITY HTN 3: the death knell for renal denervation in hypertension? Glob Cardiol Sci Pract. 2014;2014(1):94-98.

9. Bhatt DL, Kandzari DE, O'Neill WW, et al. A controlled trial of renal denervation for resistant hypertension. $N$ Engl J Med. 2014; 370(15):1393-1401.

10. DiBona GF. Sympathetic nervous system and hypertension. Hypertension. 2013;61(3):556-560.

11. Del Colle S, Morello F, Rabbia F, et al. Antihypertensive drugs and the sympathetic nervous system. J Cardiovasc Pharmacol. 2007;50(5): 487-496.

12. Patel HC, Rosen SD, Lindsay A, Hayward C, Lyon AR, di Mario C. Targeting the autonomic nervous system: measuring autonomic function and novel devices for heart failure management. Int J Cardiol. 2013 170(2):107-117

13. Esler M, Jennings G, Biviano B, Lambert G, Hasking G. Mechanism of elevated plasma noradrenaline in the course of essential hypertension. J Cardiovasc Pharmacol. 1986;8(Suppl 5):S39-S43.

14. Grassi G, Colombo M, Seravalle G, Spaziani D, Mancia G. Dissociation between muscle and skin sympathetic nerve activity in essential hypertension, obesity, and congestive heart failure. Hypertension. 1998;31(1):64-67.

15. DiBona GF, Esler M. Translational medicine: the antihypertensive effect of renal denervation. Am J Physiol Regul Integr Comp Physiol 2010;298(2):R245-R253.

16. Winternitz SR, Oparil S. Importance of the renal nerves in the pathogenesis of experimental hypertension. Hypertension. 1982;4(5 Pt 2): III108-III114.

17. DiBona GF. Neural control of the kidney: functionally specific renal sympathetic nerve fibers. Am J Physiol Regul Integr Comp Physiol. 2000;279(5):R1517-R1524.

18. Sakakura K, Tunev S, Yahagi K, et al. Comparison of histopathologic analysis following renal sympathetic denervation over multiple time points. Circ Cardiovasc Interv. 2015;8(2):doi:10.1161/ circinterventions.1114.001813.

19. Katholi RE, Rocha-Singh KJ, Goswami NJ, Sobotka PA. Renal nerves in the maintenance of hypertension: a potential therapeutic target. Curr Hypertens Rep. 2010;12(3):196-204.

20. Krum H, Schlaich M, Whitbourn R, et al. Catheter-based renal sympathetic denervation for resistant hypertension: a multicentre safety and proof-of-principle cohort study. Lancet. 2009;373(9671):1275-1281.

21. Stella A, Zanchetti A. Functional role of renal afferents. Physiol Rev. 1991;71(3):659-682.
22. Sobotka PA, Krum H, Bohm M, Francis DP, Schlaich MP. The role of renal denervation in the treatment of heart failure. Curr Cardiol Rep. 2012;14(3):285-292.

23. Hausberg M, Kosch M, Harmelink P, et al. Sympathetic nerve activity in end-stage renal disease. Circulation. 2002;106(15):1974-1979.

24. Schlaich MP, Sobotka PA, Krum H, Lambert E, Esler MD. Renal sympathetic-nerve ablation for uncontrolled hypertension. $N$ Engl $J$ Med. 2009;361(9):932-934.

25. Peet MM. Hypertension and its surgical treatment by bilateral supradiaphragmatic splanchnicectomy. Am J Surg. 1948;75(1):48-68.

26. Smithwick R. Surgical treatment of hypertension: the effect of radical (lumbodorsal) splanchnicectomy on the hypertensive state of one hundred and fifty-six patients followed one to five years. Arch Surg. 1944;49(3):180-193.

27. Gazdar AF, Dammin GJ. Neural degeneration and regeneration in human renal transplants. N Engl J Med. 1970;283(5):222-224.

28. Hansen JM, Abildgaard U, Fogh-Andersen N, et al. The transplanted human kidney does not achieve functional reinnervation. Clin Sci (Lond). 1994;87(1):13-20.

29. Booth LC, Nishi EE, Yao ST, et al. Reinnervation of renal afferent and efferent nerves at 5.5 and 11 months after catheter-based radiofrequency renal denervation in sheep. Hypertension. 2015;65(2):393-400.

30. Kline RL, Mercer PF. Functional reinnervation and development of supersensitivity to NE after renal denervation in rats. Am J Physiol. 1980;238(5):R353-R358.

31. Sankari B, Stowe N, Gavin JP, Satoh S, Nally JV, Novick AC. Studies on the afferent and efferent renal nerves following autotransplantation of the canine kidney. J Urol. 1992;148(1):206-210.

32. Getts RT, Hazlett SM, Sharma SB, et al. Regression of left ventricular hypertrophy after bilateral nephrectomy. Nephrol Dial Transplant. 2006;21(4):1089-1091.

33. Daugherty SL, Powers JD, Magid DJ, et al. Incidence and prognosis of resistant hypertension in hypertensive patients. Circulation. 2012; 125(13):1635-1642.

34. Patel H, Hayward C, de Silva R. An approach to diagnosis and management of resistant hypertension. J Pract Cardiovasc Sci. 2015;1(1):60.

35. Pimenta E, Calhoun DA. Resistant hypertension: incidence, prevalence and prognosis. Circulation. 2012;125(13):1594-1596.

36. Patel HC, Hayward C, Ozdemir BA, et al. Magnitude of blood pressure reduction in the placebo arms of modern hypertension trials: implications for trials of renal denervation. Hypertension. 2014;65(2): 401-406.

37. Atherton DS, Deep NL, Mendelsohn FO. Micro-anatomy of the renal sympathetic nervous system: a human postmortem histologic study. Clin Anat. 2012;25(5):628-633.

38. Sakakura K, Ladich E, Cheng Q, et al. Anatomic assessment of sympathetic peri-arterial renal nerves in man. $J$ Am Coll Cardiol. 2014; 64(7):635-643.

39. Patel H, Dhillon P, Mahfoud F, et al. The biophysics of renal sympathetic denervation using radiofrequency energy. Clin Res Cardiol. 2014;103(5):337-344.

40. Henegar JR, Zhang Y, Hata C, Narciso I, Hall ME, Hall JE. Catheter-based radiofrequency renal denervation: location effects on renal norepinephrine. Am J Hypertens. 2015;28(7):909-914.

41. Patel HC, Otero S, Moser JB, et al. A cross-sectional imaging study to identify organs at risk of thermal injury during renal artery sympathetic denervation. Int J Cardiol. 2015;197:235-240.

42. Henegar JR, Zhang Y, De Rama R, Hata C, Hall ME, Hall JE. Catheterbased radiorefrequency renal denervation lowers blood pressure in obese hypertensive dogs. Am J Hypertens. 2014;27(10):1285-1292.

43. Vink EE, Goldschmeding R, Vink A, Weggemans C, Bleijs RL, Blankestijn PJ. Limited destruction of renal nerves after catheter-based renal denervation: results of a human case study. Nephrol Dial Transplant. 2014;29(8):1608-1610.

44. Sakakura K, Ladich E, Edelman ER, et al. Methodological standardization for the pre-clinical evaluation of renal sympathetic denervation. JACC Cardiovasc Interv. 2014;7(10):1184-1193. 
45. Chinushi M, Izumi D, Iijima $\mathrm{K}$, et al. Blood pressure and autonomic responses to electrical stimulation of the renal arterial nerves before and after ablation of the renal artery. Hypertension. 2013;61(2): 450-456.

46. Krum H, Schlaich MP, Sobotka PA, et al. Percutaneous renal denervation in patients with treatment-resistant hypertension: final 3-year report of the Symplicity HTN-1 study. Lancet. 2014;383(9917):622-629.

47. Howard JP, Nowbar AN, Francis DP. Size of blood pressure reduction from renal denervation: insights from meta-analysis of antihypertensive drug trials of 4,121 patients with focus on trial design: the CONVERGE report. Heart. 2013;99(21):1579-1587.

48. Law MR, Morris JK, Wald NJ. Use of blood pressure lowering drugs in the prevention of cardiovascular disease: meta-analysis of 147 randomised trials in the context of expectations from prospective epidemiological studies. BMJ. 2009;338:b1665.

49. de la Sierra A, Segura J, Banegas JR, et al. Clinical features of 8295 patients with resistant hypertension classified on the basis of ambulatory blood pressure monitoring. Hypertension. 2011;57(5):898-902.

50. Mahfoud F, Ukena C, Schmieder RE, et al. Ambulatory blood pressure changes after renal sympathetic denervation in patients with resistant hypertension. Circulation. 2013;128(2):132-140.

51. Howard JP, Cole GD, Sievert H, et al. Unintentional overestimation of an expected antihypertensive effect in drug and device trials: mechanisms and solutions. Int J Cardiol. 2014;172(1):29-35.

52. Howard JP, Patel H, Shun-Shin MJ, et al. Impact of number of prescribed medications on visit-to-visit variability of blood pressure: implications for design of future trials of renal denervation. J Hypertens. 2015;33(11):2359-2367.

53. Kandzari DE, Bhatt DL, Brar S, et al. Predictors of blood pressure response in the SYMPLICITY HTN-3 trial. Eur Heart J. 2015;36(4): 219-227.

54. Desch S, Okon T, Heinemann D, et al. Randomized sham-controlled trial of renal sympathetic denervation in mild resistant hypertension. Hypertension. 2015;65(6):1202-1208.

55. Rosa J, Widimsky P, Tousek P, et al. Randomized comparison of renal denervation versus intensified pharmacotherapy including spironolactone in true-resistant hypertension: six-month results from the Prague-15 study. Hypertension. 2015;65(2):407-413.

56. Azizi M, Sapoval M, Gosse P, et al. Optimum and stepped care standardised antihypertensive treatment with or without renal denervation for resistant hypertension (DENERHTN): a multicentre, open-label, randomised controlled trial. Lancet. 2015;385(9981):1957-1965.

57. Kario K, Ogawa H, Okumura K, et al. SYMPLICITY HTN-Japan - first randomized controlled trial of catheter-based renal denervation in Asian patients. Circ J. 2015;79(6):1222-1229.

58. Pokushalov E, Romanov A, Corbucci G, et al. A randomized comparison of pulmonary vein isolation with versus without concomitant renal artery denervation in patients with refractory symptomatic atrial fibrillation and resistant hypertension. JAm Coll Cardiol. 2012;60(13): $1163-1170$

59. Staessen JA, Jin Y, Thijs L, Persu A, Azizi M, Kjeldsen S. First-in-man randomized clinical trial of renal denervation for atrial arrhythmia raises concern. J Am Coll Cardiol. 2013;62(21):e445-e446.

60. Gal P, de Jong MR, Smit JJ, Adiyaman A, Staessen JA, Elvan A. Blood pressure response to renal nerve stimulation in patients undergoing renal denervation: a feasibility study. $J$ Hum Hypertens. 2015;29(5):292-295.

61. Fadl Elmula FEM, Jin Y, Yang WY, et al. Meta-analysis of randomized controlled trials of renal denervation in treatment-resistant hypertension. Blood Press. 2015;24(5):263-274.

62. Karanasos A, Van Mieghem N, Bergmann MW, et al. Multimodality intra-arterial imaging assessment of the vascular trauma induced by balloon-based and nonballoon-based renal denervation systems. Circ Cardiovasc Interv. 2015;8(7): 002474.

63. Burnier M, Santschi V, Favrat B, Brunner HR. Monitoring compliance in resistant hypertension: an important step in patient management. J Hypertens Suppl. 2003;21(2):S37-S42.
64. Jung O, Gechter JL, Wunder C, et al. Resistant hypertension? Assessment of adherence by toxicological urine analysis. J Hypertens. 2013;31(4):766-774.

65. Navar LG. Counterpoint: activation of the intrarenal renin-angiotensin system is the dominant contributor to systemic hypertension. $J \mathrm{Appl}$ Physiol (1985). 2010;109(6):1998-2000; discussion 2015.

66. Vink EE, Verloop WL, Siddiqi L, van Schelven LJ, Liam Oey P, Blankestijn PJ. The effect of percutaneous renal denervation on muscle sympathetic nerve activity in hypertensive patients. Int J Cardiol. 2014; 176(1):8-12.

67. Hering D, Marusic P, Walton AS, et al. Sustained sympathetic and blood pressure reduction 1 year after renal denervation in patients with resistant hypertension. Hypertension. 2014;64(1):118-124.

68. Ahmed H, Neuzil P, Skoda J, et al. Renal sympathetic denervation using an irrigated radiofrequency ablation catheter for the management of drug-resistant hypertension. JACC Cardiovasc Interv. 2012;5(7):758-765.

69. Bartus K, Sadowski J, Kapelak B, et al. Denervation of nerve terminals in renal arteries: one-year follow-up of interventional treatment of arterial hypertension. Kardiol Pol. 2014;72(5):425-431.

70. Bakris GL, Townsend RR, Flack JM, et al. 12-month blood pressure results of catheter-based renal artery denervation for resistant hypertension: the SYMPLICITY HTN-3 trial. $J$ Am Coll Cardiol. 2015;65(13):1314-1321.

71. Bausback Y, Friedenberger J, Hertting K, et al. Renal denervation for hypertension refractory to renal artery stenting. J Endovasc Ther. 2014;21(2):181-190.

72. Böhm M, Mahfoud F, Ukena C, et al. First report of the Global SYMPLICITY Registry on the effect of renal artery denervation in patients with uncontrolled hypertension. Hypertension. 2015;65(4):766-774.

73. Brinkmann J, Heusser K, Schmidt BM, et al. Catheter-based renal nerve ablation and centrally generated sympathetic activity in difficult-tocontrol hypertensive patients: prospective case series. Hypertension. 2012;60(6):1485-1490.

74. Courand PY, Dauphin R, Rouvière O, et al. [Renal denervation for treating hypertension: experience at the University Hospital in Lyon]. Ann Cardiol Angeiol (Paris). 2014;63(3):183-188. French.

75. Damascelli B, Patelli G, Tichá V, et al. Catheter-based radiofrequency renal sympathetic denervation for resistant hypertension. J Vasc Interv Radiol. 2013;24(5):632-639.

76. Dong H, Jiang X, Liang T, et al. Transradial renal denervation for the treatment of resistant hypertension. J Invasive Cardiol. 2014;26(7):322-327.

77. Dong H, Jiang X, Liang T, et al. One-year outcomes of percutaneous renal denervation for the treatment of resistant hypertension: the first Chinese experience. Chin Med J (Engl). 2014;127(6):1003-1007.

78. Dorr O, Liebetrau C, Mollmann H, et al. Soluble fms-like tyrosine kinase-1 and endothelial adhesion molecules (intercellular cell adhesion molecule-1 and vascular cell adhesion molecule-1) as predictive markers for blood pressure reduction after renal sympathetic denervation. Hypertension. 2014;63(5):984-990.

79. Ewen S, Ukena C, Linz D, et al. Reduced effect of percutaneous renal denervation on blood pressure in patients with isolated systolic hypertension. Hypertension. 2015;65(1):193-199.

80. Fadl Elmula FE, Hoffmann P, Fossum E, et al. Renal sympathetic denervation in patients with treatment-resistant hypertension after witnessed intake of medication before qualifying ambulatory blood pressure. Hypertension. 2013;62(3):526-532.

81. Hart EC, McBryde FD, Burchell AE, et al. Translational examination of changes in baroreflex function after renal denervation in hypertensive rats and humans. Hypertension. 2013;62(3):533-541.

82. Honton B, Pathak A, Sauguet A, Fajadet J. First report of transradial renal denervation with the dedicated radiofrequency Iberis ${ }^{\mathrm{TM}}$ catheter. EuroIntervention. 2014;9(12):1385-1388.

83. Id D, Kaltenbach B, Bertog SC, et al. Does the presence of accessory renal arteries affect the efficacy of renal denervation? JACC Cardiovasc Interv. 2013;6(10):1085-1091. 
84. Kaiser L, Beister T, Wiese A, et al. Results of the ALSTER BP realworld registry on renal denervation employing the Symplicity system. EuroIntervention. 2014;10(1):157-165.

85. Kiuchi MG, Maia GL, de Queiroz Carreira MA, et al. Effects of renal denervation with a standard irrigated cardiac ablation catheter on blood pressure and renal function in patients with chronic kidney disease and resistant hypertension. Eur Heart J. 2013;34(28):2114-2121.

86. Korovesis S, Giazitzoglou E, Pantos I, et al. Renal denervation for resistant hypertension: acute results and long-term follow-up. Hellenic J Cardiol. 2014;55(3):211-216.

87. Krum H, Schlaich MP, Sobotka PA, et al. Percutaneous renal denervation in patients with treatment-resistant hypertension: final 3-year report of the Symplicity HTN-1 study. Lancet. 2014;383(9917):622-629.

88. Lambert T, Nahler A, Reiter C, et al. Influence of pseudo-resistance on the effect of renal denervation on 24-hour ambulatory blood pressure levels. Catheter Cardiovasc Interv. 2015;86(3):126-130.

89. Luetkens JA, Wilhelm K, Düsing R, et al. Renal denervation: results of a single-center cohort study. Rofo. 2015;187(1):36-41.

90. Mabin T, Sapoval M, Cabane V, Stemmett J, Iyer M. First experience with endovascular ultrasound renal denervation for the treatment of resistant hypertension. EuroIntervention. 2012;8(1):57-61.

91. Mahfoud F, Ukena C, Schmieder RE, et al. Ambulatory blood pressure changes after renal sympathetic denervation in patients with resistant hypertension. Circulation. 2013;128(2):132-140.

92. Ormiston JA, Watson T, van Pelt N, et al. Renal denervation for resistant hypertension using an irrigated radiofrequency balloon: 12-month results from the Renal Hypertension Ablation System (RHAS) trial. EuroIntervention. 2013;9(1):70-74.

93. Ott C, Janka R, Schmid A, et al. Vascular and renal hemodynamic changes after renal denervation. Clin J Am Soc Nephrol. 2013;8(7):1195-1201.

94. Ott C, Mahfoud F, Schmid A, et al. Improvement of albuminuria after renal denervation. Int $J$ Cardiol. 2014;173(2):311-315.

95. Ott C, Mahfoud F, Schmid A, et al. Renal denervation in moderate treatment-resistant hypertension. J Am Coll Cardiol. 2013;62(20):1880-1886.

96. Persu A, Jin Y, Azizi M, et al. Blood pressure changes after renal denervation at 10 European expert centers. J Hum Hypertens. 2014;28(3):150-156.

97. Prochnau D, Heymel S, Gobel B, Figulla HR, Surber R. Resistant hypertension: multivariate predictors of blood pressure response to renal denervation. Int J Cardiol. 2013;168(3):3130-3132.

98. Schlaich MP, Bart B, Hering D, et al. Feasibility of catheter-based renal nerve ablation and effects on sympathetic nerve activity and blood pressure in patients with end-stage renal disease. Int J Cardiol. 2013;168(3):2214-2220.

99. Scheurig-Muenkler C, Weiss W, Foert E, et al. Renal denervation for refractory hypertension - technical aspects, complications and radiation exposure. Rofo. 2013;185(6):550-557.

100. Schwerg M, Heupel C, Strajnic D, et al. Renal sympathetic denervation: early impact on ambulatory resistant hypertension. J Clin Hypertens (Greenwich). 2014;16(6):406-411.
101. Templin C, Jaguszewski M, Ghadri JR, et al. Vascular lesions induced by renal nerve ablation as assessed by optical coherence tomography: pre- and post-procedural comparison with the Simplicity catheter system and the EnligHTN multi-electrode renal denervation catheter. Eur Heart J. 2013;34(28):2141-2148, 2148b.

102. Tuohy ST, Kyvelou SG, Gleeson PJ, et al. The effect of renal sympathetic denervation on nocturnal dipping in patients with resistant hypertension; observational data from a tertiary referral centre in the Republic of Ireland. Ir J Med Sci. Epub 2015 Jun 19.

103. Vase H, Mathiassen ON, Kaltoft A, et al. Catheter-based renal denervation for treatment of resistant hypertension. Dan Med J 2012;59(6):A4439.

104. Verloop WL, Vink EE, Spiering W, et al. Renal denervation in multiple renal arteries. Eur J Clin Invest. 2014;44(8):728-735.

105. Versaci F, Trivisonno A, Olivieri C, Caranci F, Brunese L, Prati F. Vascular response after percutaneous sympathectomy: not all devices are equal. Int J Cardiol. 2014;174(2):406-407.

106. Vogel B, Kirchberger M, Zeier M, et al. Renal sympathetic denervation therapy in the real world: results from the Heidelberg registry. Clin Res Cardiol. 2014;103(2):117-124.

107. Volz S, Andersson B, Manhem K, Haraldsson I, Rundqvist B. Effect of catheter-based renal sympathetic denervation on 24-h ambulatory blood pressure in patients with resistant hypertension. Blood Pressure. 2014;23(4):228-232

108. Witkowski A, Prejbisz A, Florczak E, et al. Effects of renal sympathetic denervation on blood pressure, sleep apnea course, and glycemic control in patients with resistant hypertension and sleep apnea. Hypertension. 2011;58(4):559-565.

109. Worthley SG, Tsioufis CP, Worthley MI, et al. Safety and efficacy of a multi-electrode renal sympathetic denervation system in resistant hypertension: the EnligHTN I trial. Eur Heart J. 2013;34(28):2132-2140.

110. Ewen S, Mahfoud F, Linz D, et al. Effects of renal sympathetic denervation on exercise blood pressure, heart rate, and capacity in patients with resistant hypertension. Hypertension. 2014;63(4):839-845.

111. Hering D, Lambert EA, Marusic P, et al. Renal nerve ablation reduces augmentation index in patients with resistant hypertension. J Hypertens. 2013;31(9):1893-1900.

112. Mahfoud F, Cremers B, Janker J, et al. Renal hemodynamics and renal function after catheter-based renal sympathetic denervation in patients with resistant hypertension. Hypertension. 2012;60(2):419-424.

113. Mahfoud F, Schlaich M, Kindermann I, et al. Effect of renal sympathetic denervation on glucose metabolism in patients with resistant hypertension: a pilot study. Circulation. 2011;123(18):1940-1946.

114. Zhang ZH, Yang K, Jiang FL, Zeng LX, Jiang WH, Wang XY. The effects of catheter-based radiofrequency renal denervation on renal function and renal artery structure in patients with resistant hypertension. J Clin Hypertens (Greenwich). 2014;16(8):599-605.
Integrated Blood Pressure Control

\section{Publish your work in this journal}

Integrated Blood Pressure Control is an international, peer-reviewed open-access journal focusing on the integrated approach to managing hypertension and risk reduction. Treating the patient and comorbidities together with diet and lifestyle modification and optimizing healthcare resources through a multidisciplinary team approach constitute key

\section{Dovepress}

features of the journal. This journal is indexed on American Chemical Society's Chemical Abstracts Service (CAS). The manuscript management system is completely online and includes a very quick and fair peerreview system, which is all easy to use. Visit http://www.dovepress.com/ testimonials.php to read real quotes from published authors. 